\title{
Sea ice concentration temporal variability over the Weddell Sea and its relationship with tropical sea surface temperature
}

\author{
S. Barreira ${ }^{1}$ and R. Compagnucci ${ }^{2}$ \\ ${ }^{1}$ Argentine Navy Meteorological Service, Bs. As., Argentina, barreira@ara.mil.ar \\ ${ }^{2}$ Universidad de Buenos Aires, Departamento de Cs. de la Atmósfera y los Océanos, Bs. As., Argentina, rhc@at.fcen.uba.ar
}

\begin{abstract}
Principal Components Analysis (PCA) in S-Mode (correlation between temporal series) was performed on sea ice monthly anomalies, in order to investigate which are the main temporal patterns, where are the homogenous areas located and how are they related to the sea surface temperature (SST). This analysis provides 9 patterns (4 in the Amundsen and Bellingshausen Seas and 5 in the Weddell Sea) that represent the most important temporal features that dominated sea ice concentration anomalies (SICA) variability in the Weddell, Amundsen and Bellingshausen Seas over the 1979-2000 period. Monthly Polar Gridded Sea Ice Concentrations data set derived from satellite information generated by NASA Team algorithm and acquired from the National Snow and Ice Data Center (NSIDC) were used. Monthly means SST are provided by the National Center for Environmental Prediction reanalysis. The first temporal pattern series obtained by PCA has its homogeneous area located at the external region of the Weddell and Bellingshausen Seas and Drake Passage, mostly north of $60^{\circ} \mathrm{S}$. The second region is centered in $30^{\circ} \mathrm{W}$ and located at the southeast of the Weddell. The third area is localized east of $30^{\circ} \mathrm{W}$ and north of $60^{\circ} \mathrm{S}$. South of the first area, the fourth PC series has its homogenous region, between $30^{\circ}$ and $60^{\circ} \mathrm{W}$. The last area is centered at $0^{\circ} \mathrm{W}$ and south of $60^{\circ} \mathrm{S}$. Correlation charts between the five Principal Components series and SST were performed. Positive correlations over the Tropical Pacific Ocean were found for the five PCs when SST series preceded SICA PC series. The sign of the correlation could relate the occurrence of an El Niño/Southern Oscillation (ENSO) warm (cold) event with posterior positive (negative) anomalies of sea ice concentration over the Weddell Sea.

Citation: Barreira, S. and C. Compagnucci (2007), Sea ice concentration temporal variability over the Weddell Sea and its relationship with tropical sea surface temperature, in Antarctica: A Keystone in a Changing World - Online Proceedings of the 10th ISAES, edited by A. K. Cooper and C. R. Raymond et al., USGS Open-File Report 2007-1047, Short Research Paper 029, 5 p.; doi:10.3133/of2007-1047.srp029.
\end{abstract}

\section{Introduction}

A wide range of studies had been focused on the identification and characterization of the dominant pattern of Antarctic sea ice time variability from inter-annual to inter-decadal scale. White and Peterson (1996) and Jacobs and Mitchell (1996) identified a coupled air-sea-ice pattern of inter-annual anomalies in atmospheric pressure at sea level, wind stress, sea surface temperature and seaice extent in the Southern Ocean. This pattern, referred as the Antarctic Circumpolar Wave, propagates eastwards in a wave train with the circumpolar flow characterized by a wavenumber-2 pattern, with a periodicity of 4-5 years. The ACW has the major source of interannual sea surface temperature (SST) anomalies in the western subtropical South Pacific ocean, that are driven by El Niño/Southern Oscillation (ENSO), through the influence of the Hadley cell (Peterson and White, 1998).

Yuan and Martinson (2001) called "Antarctic Dipole" (ADP) to the dominant inter-annual variability in the sea ice edge and surface air temperature fields organized as a quasi-stationary wave with poles centered in the northeastern Ross Gyre in the Pacific sector, and the central Weddell Gyre in the Atlantic sector of the Southern Oceans. The ADP is characterized by an out-ofphase association between the ice and temperature anomalies in the central/eastern Pacific and Atlantic sectors of the Antarctic and, is associated with the ENSO.

An atmosphere wave train of climate anomalies links equatorial with polar latitudes in the Pacific Ocean during ENSO events. According to Houseago et al., (1998) there is a propagation of height and temperature anomalies from subtropical to high latitudes up to the event peak with these persisting for about a year in sub polar latitudes. Harangozo (2000) showed that ENSO teleconnections indirectly reach west Antarctic Peninsula winter temperatures via alterations in the local ice extent and that above-normal pre-winter ice extent is a necessary condition for cold winters but wintertime ice extent changes with ENSO-related meridional flow variations. Yuan (2004) studied the composite analysis for five El Niño and five La Niña events to determine the relationship between Antarctic sea ice and climatic variables, finding a positive feedback between the polar jet stream and stationary eddies in the atmosphere and, within the air-sea-ice system that reinforces the anomalies, resulting in long-lasting ADP anomalies. Moreover, the transmission of the ENSO signal to higher latitudes and the evidence in the Antarctic meteorological and sea ice records has been widely discussed by Turner (2004) in his extensive review of the results present in literature. He concluded that "we currently have a poor understanding of the transfer functions by which such signals arrive at the Antarctic from the tropical Pacific" and that ENSO-sea ice links have shown "the complex nature of the connections that are functions of the season and the sector of the Antarctic".

Undoubtedly, increasing the knowledge of sea ice condition and the relationship between its variability and atmospheric circulation in the Antarctic Peninsula area is an important task. According to Yuan and Martinson (2000) the Amundsen, Bellingshausen and Weddell Seas 
correspond to the sector that record the main sea ice variability of the Southern Ocean.

The aim of this study is to analyze the temporal variability of sea ice in the Weddell Seas and its ENSO teleconnections. For this reason, the leading temporal patterns of monthly sea ice concentration anomalies (SICA) were obtained by means of Principal Component Analysis in S-mode based on a correlation input matrix among temporal series (S-mode following Richman 1986, Preisendorfer, 1988). This approach gives the temporal patterns and their localization in space (homogeneous area). In that way, the relationship between SICA temporal structure and sea surface temperature can be established.

\section{Data and method}

Monthly Polar Gridded Sea Ice Concentrations data set (ocean fraction covered by sea ice) derived from the Nimbus-7 Scanning Multichannel Microwave Radiometer (SMMR) and the Defense Meteorological Satellite Program's (DMSP) DMSP-F8, F11 and F13, Special Sensor Microwave/Imager (SSM/I) generated by NASA team algorithm (developed by the Oceans and Ice Branch, Laboratory for Hydrospheric Processes at NASA Goddard Space Flight Center) were used. This product was designed to provide a consistent time series of sea ice concentrations spanning the coverage of several passive microwave instruments. To aid in this goal, sea ice algorithm coefficients were changed to reduce differences in sea ice extent and area as estimated using the SMMR and SSM/I sensors due to the fact that during overlap periods, data were available from two instruments and differences in ice covered area and ice extent during the overlap periods were minimized by tuning the sea ice algorithms. These data were acquired from the National Snow and Ice Data Center (NSIDC) and is gridded on the $\mathrm{SSM} / \mathrm{I}$ polar stereographic grid $(25 \times 25 \mathrm{~km})$ (Cavalieri, D. et al 1999, updated 2002). The sea ice concentration anomalies with respect to the annual cycle were obtained removing the monthly averages of long term. The values ranged from $0 \%$ (for no sea ice in the grid area) to $100 \%$ (for a completely ice-covered grid area). Monthly means SST are provided by the National Center for Atmospheric Research/National Center for Environmental Prediction reanalysis data (Kalnay et al, 1996) with a resolution of $2.5^{\circ}$ latitude by $2.5^{\circ}$ longitude.

To obtain the series of principal components (PCs) and the Component Loadings (homogeneous subregions), Principal Component Analysis (PCA), was performed using the correlation matrix among the 22,000 SICA time series (S-Mode) over the area between $0^{\circ}$ and $120^{\circ} \mathrm{W}$ and $50^{\circ}$ and $90^{\circ} \mathrm{S}$. This region comprised not only the Weddell Sea but the Bellingshausen and part of the Amundsen Seas. The PCs were Varimax rotated iteratively retaining 2 to 20 components. In each case, the congruence coefficient was calculated to determinate the quality of the adjustment that maximize the physical meaning of the results. The best adjustment was obtained for six PCs that regionalized nine sub-areas. The PCs that correspond to sub-areas over the Weddell Sea explained the $33.4 \%$ of the total temporal variance for the whole region (there is a $25.2 \%$ of the variance explained by the PCs that correspond to the Bellingshausen and Amundsen Seas, not shown in this paper). The PCA analysis was performed as a first exploratory step. To obtain temporal patterns, the composition of the real SICA series within the area with the higher principal component loadings $(C L \geq|0.75|)$ for the corresponding PCs series were used instead of the PCs obtained by the PCA methods. The final homogeneous sub-regions were readjusted by means of correlation between the temporal patterns and the SICA series. Monthly lagged spatial correlation analysis $(+24$ to -24 months) was used to analyze the possible magnitude of the connection, between temporal SICA patterns and Tropical SST. Positive lags indicate SST series are previous to SICA pattern series.

\section{Temporal patterns, homogeneous areas and sea surface temperature}

Figure 1a presents the $1^{\text {st }}$ temporal pattern series that corresponds to the northwest of the Weddell and the northeast Bellingshausen Seas region (figure 1 bottom) and explains the $8.8 \%$ of the total variance.

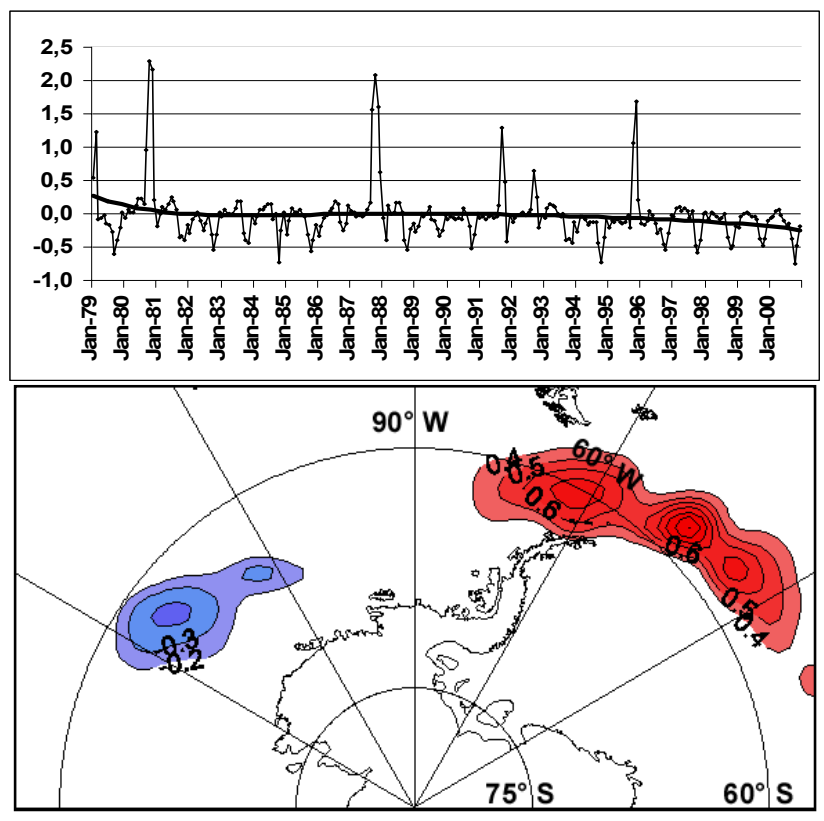

Figure 1. SICA $1^{\text {st }}$ temporal pattern obtained by the composite series for the area with CL greater than 0.75 (top), Sub-region obtained after the spatial correlation between SICA and the $1^{\text {st }}$ pattern series (bottom).

The pattern presents a negative tendency and its maximums and minimums correspond to the winterspring period. Some of the correlation fields between $1^{\text {st }}$ SICA pattern series and SST are shown in figure 2. Positive correlations with Tropical SST were found for lags +11 to +6 months suggesting that El Niño (La Niña) 
event would precede positive (negative) sea ice anomalies in this $1^{\circ}$ sub-region. Negatives correlations over the Pacific for leads -20 to -23 and -10 to -8 , could indicate than after positive (negative) SICA there will be La Niña (El Niño) event almost a year later.
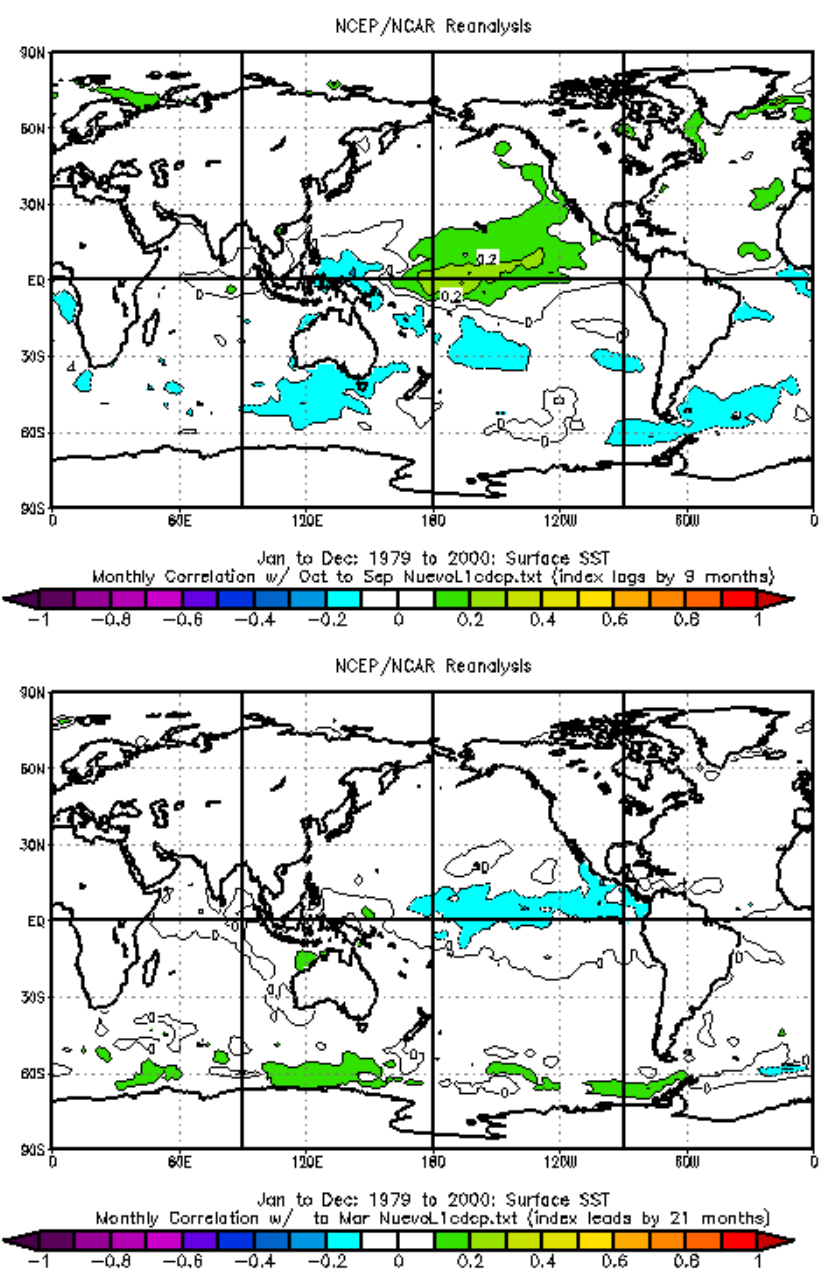

Figure 2. Correlation fields between the $1^{\text {st }}$ SICA pattern and SST for lags +9 (top) and lead -21(bottom).

Due to the fact that these are series of anomalies, the values of correlation greater than $|0.1|$ are significantly different from cero at the $95 \%$. Nevertheless, the values are small and represent a low level of explained variance although they are significant

Figure 3 (top) presents the $2^{\text {nd }}$ temporal pattern series that is related to the southeast region of the Weddell Sea and explains the $7.5 \%$ of the total variance. The maximums and minimums correspond to summer-autumn period. The correlation fields with SST (figure 4) show positive values between +7 to -9 months. This means that a positive (negative) Tropical SST anomaly would lead to a positive (negative) SICA in this region half a year later which in turn could produce a positive (negative) SST anomaly as far as 9 months after the positive SICA.
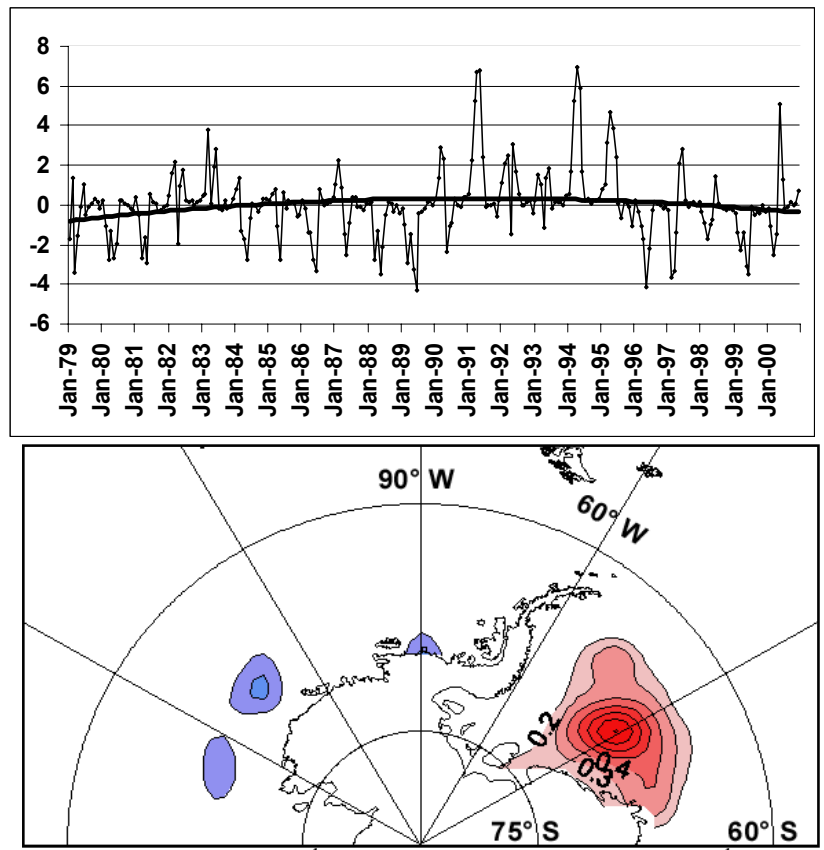

Figure 3. SICA $2^{\text {nd }}$ temporal pattern (top), $2^{\text {nd }}$ Subregion (bottom).

The $3^{\text {rd }}$ temporal pattern (not shown) has its centre of action over the northeastern Weddell Sea and southwestern Indian Ocean (figure 5) northward $60^{\circ} \mathrm{S}$. The series explains the $6 \%$ of the total variance and shows alternate maximums and minimums during winter and spring. The correlation fields (not shown) present positive values between +9 and +24 months, showing no relationship when sea ice anomalies precede SST anomalies (negative lags or leads) and for lag 0 (simultaneous occurrence). The positive sign of the obtained correlation implies that this area could increase (reduce) its winter-spring sea ice concentration even after 2 years of a warm (cold) ENSO event.

The $4^{\text {th }}$ temporal pattern (not shown), that explains the $5.9 \%$ of the variance, shows maximums and minimums during the summer and autumn due to the fact that the corresponding homogeneous area (figure 6) is a very variable area throughout that period of the year. This region is situated south of the area determined by the $1^{\text {st }}$ temporal pattern. For this reason the temporal variability responds generally to those years when the sea ice does not reach minor latitudes but suffers a strong increase or decrease in the region south $60^{\circ} \mathrm{S}$. The correlation fields between the $4^{\text {th }}$ temporal pattern and SST (figure 7) show positive correlation for positive lags $(0$ to +24 , with greater values for lags +1 to +10 ). It could be say that $\mathrm{El}$ Niño (La Niña) event could be the cause of an increase (decrease) of winter SICA or a summer with a preservation of sea ice. Due to the fact that the correlation is high for lag 0 , both situations could exist at the same time (positive SST and positive SICA). 
The $5^{\text {th }}$ temporal pattern (not shown) corresponds to a homogeneous area located around $60^{\circ} \mathrm{S}$ and between $0^{\circ}$ and $30^{\circ} \mathrm{W}$ (southeast of the Weddell Sea, figure 8).
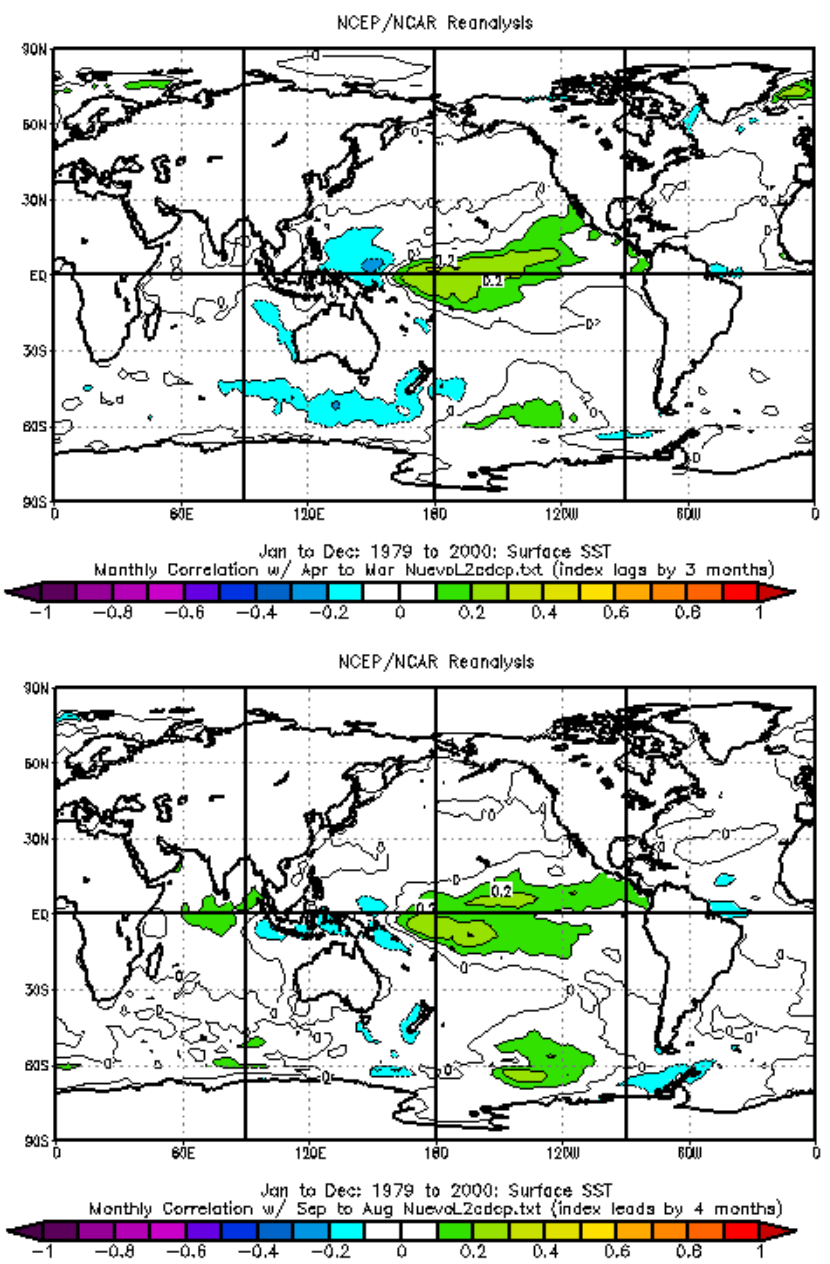

Figure 4. Correlation fields between the $2^{\text {nd }}$ SICA pattern and SST for lags +3 (top) and lead -4(bottom).

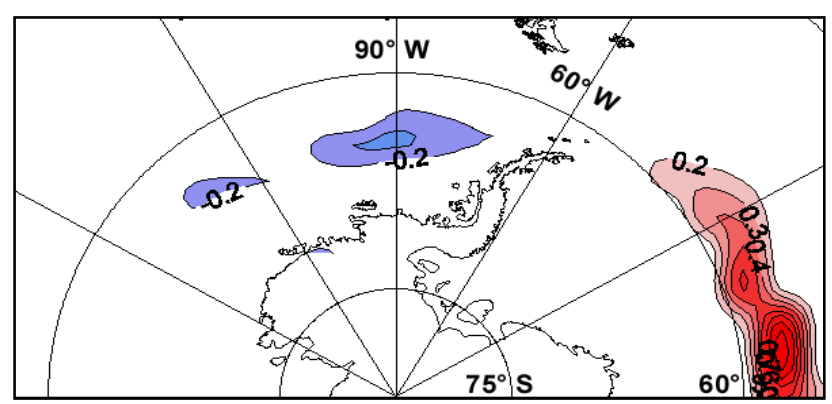

Figure 5. SICA $3^{\text {rd }}$ temporal pattern Sub-region.

The maximum and minimum values resulted of the same intensity and are registered preferably in the winter period. This pattern explains the $5.2 \%$ of the variance. The correlation fields (not shown) show positive correlations for lags +12 to +24 months before the appearance of the anomaly of sea ice at the regions Niño
4 and Niño 3.4. Due to the fact that the homogeneous area associated to this temporal pattern has its principal variability during winter and spring months, it might be possible that an ENSO occurred between one and two years before, could be a remote origin for this SICA signal.

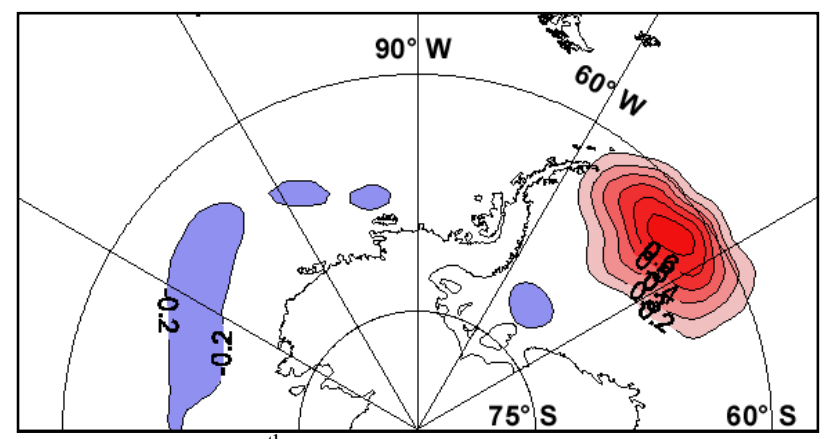

Figure 6. SICA $4^{\text {th }}$ temporal pattern Sub-region.

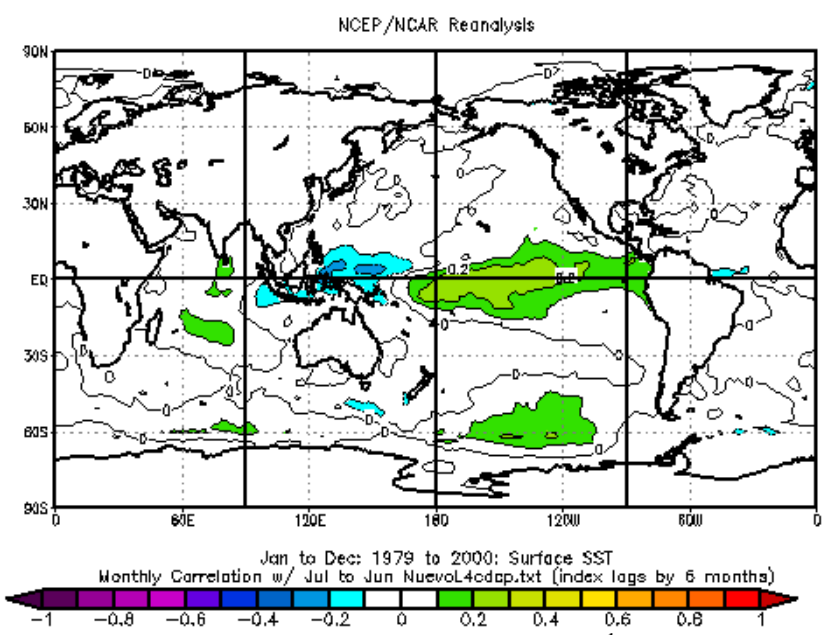

Figure 7. Correlation fields between the $4^{\text {th }}$ SICA pattern and SST for lags +6 .

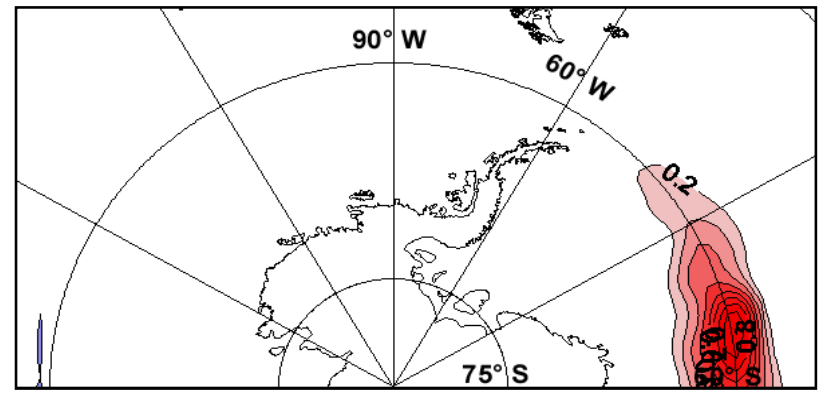

Figure 8. SICA $5^{\text {th }}$ temporal pattern Sub-region.

\section{Discussion}

Although the relationship between SST and SICA is not very strong over the Weddell Sea, positive sea ice anomalies have been seen after most El Niño events (exception 1992-93) and negative SICA after all La Niña events that have occurred during the period of analysis, in 
coincidence with the positive correlation found for all the patterns. The patterns with strongest signal over the Tropical Pacific correspond to the ones with an opposite signal over the Amundsen or Bellingshausen Seas, for lags of around one year. Accordingly with Yuan (2004) the principal process that connects Tropical SST with Antarctic's sea ice is the stationary Rossby Wave that creates an anomalous high (low) pressure system centre in the Bellingshausen Sea during warm (cold) ENSO events that generates warm (cold) temperatures and negative sea ice anomalies on the Pacific and the opposite in the Atlantic. The signal is propagated to the Weddell through the ACW. The areas defined by the PCA method covered almost all the Weddell Sea. So that, with this 5 PCs the sea ice temporal variability can be completely explain.

Acknowledgments. The author thank to the co-editor and all reviewers for their useful comments and to the National Snow and Ice Data Center and the National Center for Atmospheric Research/National Center for Environmental Prediction for the data used in this paper.

\section{References}

Cavalieri, D.C., C.L. Parkinson, P. Gloerson, and H.J. Zwally (1999, updated 2002), Sea Ice Concentrations from Nimbus-7 SMMR and DMSP SSM/I Passive Microwave Data. Boulder, CO, USA: National Snow and Ice Data Center. 4 CD-ROMs.

Harangozo, S.A. (2000), A search for ENSO teleconnections in the west Antarctic Peninsula climate in austral winter. In. J. of Clim., 20, 663679.
Houseago, R, G. McGregor, J.King, and S. Harangozo (1998), Climate anomaly wave-train patterns linking southern low and high latitudes during South Pacific warm and cold events, J. Climatol. 18, 11, 11811193.

Jacobs, G. A., and J. L. Mitchell (1996), Ocean circulation variations associated with the Antarctic Circumpolar Wave, Geophys. Res. Lett., 23, 2947-2950.

Kalnay, E., and co-authors (1996), The NCEP/NCAR 40-Year Reanalysis Project, Bull. Amer. Meteor. Soc., 77, 437-471.

Peterson, R.G., and W.B. White (1998), Slow oceanic teleconnections linking the Antarctic Circumpolar Wave with the tropical El NiñoSouthern Oscillation, J. Geophys. Res., 103, 24573-24583.

Preisendorfer, R.W. (1988), Principal Component Analysis in Meteorology and Oceanography, Elsevier, New York.

Richman. M.B. (1986), Rotation of principal components, J. Climatol., 6, 293-335.

Turner, J. (2004), The El Niño-Southern Oscillation and Antarctica, In. J. of Clim., 24, 1-31.

White, W. and R. G. Peterson (1996), An Antarctic circumpolar wave in surface pressure, wind, temperature and sea-ice extent, Nature, 380, 699-702.

Yuan, X., and D.G. Martinson (2000), Antarctic sea-ice extent variability and its global connectivity, J. Climate, 13, 1697-1717.

Yuan, X., and D.G. Martinson (2001), The Antarctic Dipole and its Predictability, Geophys. Res. Lett., 28, 3609-3612.

Yuan, X. (2004), ENSO-related impacts on Antarctic sea ice: a synthesis of phenomenon and mechanisms, Antarctic Science, 16(4), 415-425, DOI:10.1017/S0954102004002238. 